\title{
Factors and associations for physical activity in severely obese adults during a two-year lifestyle intervention
}

Objective: This study of severely obese adults participating in a two-year lifestyle intervention investigates associations between the independent variables: change in self-efficacy for physical activity (PA) in the face of psychological barriers, perceived behavioural control over PA, and PA self-identity and the dependent variable of change in objectively assessed PA. The intervention comprised four residential periods in a rehabilitation centre and combined diet, physical activity, and cognitive behavioural therapy. Materials and methods: Forty-nine severely obese adults (37 women, mean body mass index $42.1 \mathrm{~kg} / \mathrm{m}^{2}$ ) were included in the study. Assessment was done four times using questionnaires and an accelerometer. A linear mixed model based on restricted maximum likelihood was used in analyses for change over time. Associations were studied using linear regression analyses. Age, gender, and change in body mass index were used as control variables. Results: In the adjusted analyses, change in perceived behavioural control over PA was associated with change in PA (Stand. coeff. $=0.32, p=.005)$. Change in PA was not associated with either change in self-efficacy over PA in the face of psychological barriers (Stand. coeff. $=0.13, p=.259$ ) or PA selfidentity (Stand. coeff. $=-0.07, p=.538$ ). Conclusion: Perceived behavioural control may be a valid target to increase and maintain PA in severely obese adults participating in lifestyle interventions. More research is needed to investigate the process of behaviour change in this population. 
1 Randi Jepsen ${ }^{1,2}$, Eivind Aadland ${ }^{1}$, Lesley Robertson ${ }^{3}$, Merete Kristiansen ${ }^{4}$, John Roger

2 Andersen $^{1,5}$, Gerd Karin Natvig ${ }^{2}$

$3{ }^{1}$ Faculty of Health Studies, Sogn og Fjordane University College, Førde, Norway

$4{ }^{2}$ Department of Global Public Health and Primary Care, University of Bergen, Bergen, Norway

$5 \quad{ }^{3}$ Red Cross Haugland Rehabilitation Centre, Flekke, Norway

$6 \quad{ }^{4}$ Faculty of Teacher Education and Sport, Sogn og Fjordane University College, Sogndal,

7 Norway

$8 \quad{ }^{5}$ Førde Health Enterprise, Førde, Norway

9 Corresponding author:

10 Randi Jepsen, Sogn og Fjordane University College, Faculty of Health Studies, P.O. Box 523,

11 NO 6803 Førde, Norway. Telephone: +47 57722577. Fax: +47 57722501. E-mail address:

12 randi.jepsen@,hisf.no 
Introduction

14 A web of political, societal, and environmental factors contributes to the growing prevalence of overweight and obesity in Western countries (Swinburn et al., 2011). Alarmingly, the group classified as severely obese has increased the most (Sturm, 2007; Midthjell et al., 2013). In

17 obesogenic societies (Swinburn et al., 2011), the health services have responsibility to ameliorate

18 the ailing health, functioning, and quality of life experienced by severely obese individuals (van

19 Nunen et al., 2007). Thus, various obesity surgeries and lifestyle interventions have been

20 developed. Obesity surgery brings about physiological and functional changes, enforcing altered

21 eating behaviours and thus leading to weight loss (Kissler \& Settmacher, 2013). By contrast,

22 lifestyle interventions work exclusively through individual modifications and self-management of

23 health-related behaviour (Kirk et al., 2012). A weight loss of 5-10\% is regarded sufficient to gain

24 health effects and reduce the risk of obesity-related comorbidities (Tsigos et al., 2008; Dalle

25 Grave, Calugi \& El Ghoch, 2013). The most extensive weight losses are obtained through obesity

26 surgery (Karlsen et al., 2013), whereas subjects attending lifestyle interventions seem to develop

27 more favourable dietary patterns (Johnson et al., 2013). Both intervention types improve health-

28 related quality of life (Karlsen et al., 2013).

29 In combination with diet modification, physical activity (PA) constitutes a core component of

30 many lifestyle interventions for severely obese adults (Kirk et al., 2012; Dalle Grave, Calugi \& El

31 Ghoch, 2013). Studies have shown that PA impacts on weight loss and its maintenance (Catenacci

32 \& Wyatt, 2007; Butryn, Webb \& Wadden, 2011), improves body composition (Lee et al., 2005;

33 Kay \& Fiatarone Singh, 2006; Goodpaster et al., 2010), reduces risk of cardio-metabolic

34 comorbidities (Fogelholm, 2010; Goodpaster et al., 2010), and is positively associated with

35 quality of life (Bond et al., 2006; Lerdal et al., 2011; Jepsen et al., 2013) in severely obese

36 subjects. Thus, given the chronic nature of severe obesity, adherence to PA is important (Tsigos et

37 al., 2008), but unfortunately PA decreases with increasing body mass index (BMI) (Tudor-Locke 
et al., 2010; Hansen et al., 2013). Severely obese subjects face many barriers to PA, such as the excess body weight itself (Wiklund, Olsén \& Willén, 2011; Christiansen, Borge \& Fagermoen, 2012) and exposure in public (Wiklund, Olsén \& Willén, 2011). A persistent increase of PA seems

41 to be difficult (Borg et al., 2002; Tate et al., 2007). Thus, lifestyle interventions should target and

42 strengthen patients' resources for PA through provision of knowledge and skills and reinforcement of psychological factors that are likely to influence PA. Hence, self-efficacy for PA, perceived behavioural control over PA, and PA self-identity have been proposed as targets for PA interventions (Hagger, Chatzisarantis \& Biddle, 2002; Jackson, Smith \& Conner, 2003; Lorentzen, Ommundsen \& Holme, 2007; Hansen et al., 2014).

According to Bandura (Bandura, 1997), self-efficacy covers "a belief about what one can do under different sets of conditions with whatever skills one possesses" (p. 37). Self-efficacy is dynamic and modifiable (Bandura, 1997), and in relation to PA, it includes the capability of adoption and maintenance of PA in the face of psychological barriers such as feeling depressed,

51 worried, angry, or stressed (Lorentzen, Ommundsen \& Holme, 2007). Self-efficacy for PA in the 52 face of psychological barriers has shown positive associations with change in PA in community

53 samples (Lorentzen, Ommundsen \& Holme, 2007). The related concept of perceived behavioural

54 control refers to a person's "belief as to how easy or difficult performance of the behaviour is

55 likely to be” (Ajzen \& Madden, 1986, p. 457). Perceived behavioural control predicts PA

56 behaviour (Hagger, Chatzisarantis \& Biddle, 2002) and plays a role in PA behaviour change in

57 community samples (Lorentzen, Ommundsen \& Holme, 2007). Identity is a third factor

58 influencing human behaviour. Hence, there is a reciprocal reinforcing relationship between a

59 behaviour-specific identity and repetition of that behaviour. Furthermore, identity is a product of

60 interaction with others (Charng, Piliavin \& Callero, 1988). PA identity, i.e., "identifying oneself

61 as a physically active person" (Lorentzen, Ommundsen \& Holme, 2007, p. 95), has shown 
62 positive associations with self-reported PA (Jackson, Smith \& Conner, 2003) and change in PA

63 (Lorentzen, Ommundsen \& Holme, 2007) in community samples.

64 Common outcome variables in research on lifestyle interventions for severely obese adults

65 are body weight and risk factors for medical comorbidities (Anderson, Conley \& Nicholas, 2007;

66 Goodpaster et al., 2010; Danielsen et al., 2013; Karlsen, Sohagen \& Hjelmesaeth, 2013). Because

67 the pathway for these outcomes is behaviour change, it is pivotal to understand factors involved

68 in the behaviour change process. However, to our knowledge, no studies have investigated

69 associations in patterns of change between psychological factors and objectively assessed PA in

70 severely obese adults during a lifestyle intervention. Thus, the aim of this study was to investigate

71 associations between the independent variables: change $(\Delta)$ in self-efficacy, $\Delta$ perceived

72 behavioural control, and $\Delta$ self-identity and the dependent variable of $\Delta$ PA. The study hypothesis

73 was that there would be positive associations in the patterns of change between self-efficacy for

74 PA in the face of psychological barriers, perceived behavioural control over PA, and PA identity

75 and objectively assessed PA in severely obese adults participating in a two-year lifestyle

76 intervention.

\section{Materials and methods}

78 Participants and setting

79 The Haugland Obesity Study has a two-year prospective design. We assessed severely obese 80 patients before, during and between residential periods in Red Cross Haugland Rehabilitation

81 Centre (RCHRC) in Norway, where they participated in a two-year lifestyle intervention. The

82 programme was funded by the public health services. For those with jobs, the social welfare

83 system paid sick leave benefits during the residential periods. Referral to RCHRC was done by

84 general practitioners. Referred patients were called in to a two-week stay, wherein motivation for

85 change and ability to function in a group were assessed and participation in the programme was 
86 decided. Due to limited capacity of the centre, the time from referral to this assessment stay was

87 up to two years. Fifty-three patients, divided in four groups, started the actual intervention (the

88 time point which constituted the baseline of the present study) and were all offered inclusion in

89 the present study. After the intake of these four groups, the public health services reduced the

90 funding to RCHRC and cut down the intervention for new patients to a one-year programme with

91 shorter residential stays. Thus, we had to discontinue inclusion of participants.

92 Inclusion criteria for the intervention were age between $18-60$ years, and BMI $\geq 40 \mathrm{~kg} / \mathrm{m}^{2}$

93 with or without comorbidities, or $\geq 35 \mathrm{~kg} / \mathrm{m}^{2}$ with comorbidities, such as type 2 diabetes,

94 treatment-resistant hypertension, and sleep apnoea (Norwegian Directorate of Health, 2009).

95 Exclusion criteria were: referral to, or, previous obesity surgery; pregnancy; severe

96 cardiovascular disease; alcohol or substance abuse; and mental illness or physical impairment

97 that would prevent adherence to the intervention.

\section{Intervention}

99 The lifestyle intervention was a multi-component programme developed by the health

100 professionals at RCHRC, built on recommendations for best practice (Shaw et al., 2005; Kirk et

101 al., 2012; Dalle Grave, Calugi \& El Ghoch, 2013; Olander et al., 2013) and prior experience. The

102 objective was to strengthen favourable PA and diet-related behaviour. The intervention covered

10315 weeks over two years with four residential periods of six, three, three, and three weeks'

104 duration. A team of physicians, nurses, physiotherapists, exercise therapist, and dietician - many

105 with training in cognitive behavioural therapy (CBT) (Shaw et al., 2005) - delivered mandatory

106 practical and theoretical sessions on PA, diet, and CBT. The PA consisted of supervised and un-

107 supervised out- and indoor activities, in groups and individually. Brisk walking, swimming,

108 strength training, ball games, and aerobics were the predominant activities during the residential

109 periods, bringing on moderate to high intensities of PA. The scheduled PA lasted 20-60 minutes 
110 per session, in total nine to eleven hours per week. In addition, the patients were encouraged to

111 carry out PA on their own initiative. Taking preferences, limitations, and sustainability into

112 account, each patient developed a plan for PA for home periods and discussed it with staff.

113 Patients were recommended to combine endurance and strength training and undertake at least 60

114 daily minutes of PA, which could be divided in intervals of down to ten minutes (Becker et al.,

115 2004). Thus, no standard exercise programme was performed in the home periods. The main goal

116 regarding diet was adaptation to a sustainable, healthy diet and a favourable eating-pattern. The

117 meal plan at RCHRC was based on the Nordic Nutrition Recommendations (Becker et al., 2004)

118 with three low-fat, high-fibre, and energy-reduced meals and two to three snacks per day. Most of

119 the meals were provided by the canteen. However, the patients prepared some of their meals in

120 supervised groups, and they ate together. They were advised to follow the same dietary principles

121 at home. Thus, severe energy-restriction was not applied. In total, eleven group sessions of CBT,

122 led by members of the health care team, took place, five during the six-week residential period

123 and two during each of the subsequent three three-week periods. Before the end of each session,

124 home work was given, and the following session started with a review of that. In sessions 1-5,

125 during the first stay, the methods and instruments of CBT were introduced and related to change

126 in PA and eating. When the patients came back for the subsequent periods, experiences from the

127 home periods were discussed in sessions 6-11 within the framework of CBT. For eight patients

128 who expressed a need, individual CBT was also provided.

129 Planning, barrier identification, and relapse prevention and management were practiced to

130 strengthen self-management of PA and eating (Olander et al., 2013). The group-based activities

131 aimed at stimulating peer support (Olander et al., 2013). Self-monitoring in home periods was

132 promoted using PA diaries (Olander et al., 2013) in which patients reported on PA and a few

133 added information on diet and success stories. All patients sent their diaries to RCHRC every

134 month. There was no other structured follow-up between the residential periods. Patients were 
135

136

137 Measures and procedures

138 Data were collected four times between February 2010 and October 2012 (Figure 1). The first

139 collection, baseline, was done prior to the start of the intervention, the second at the end of the

140 first residential stay and the third before the third stay, one year from baseline. The final data

141 collection took place before the fourth and last stay, two years from baseline. Socio-demographic

142 data in this study are baseline data.

143 Psychological factors

144 The psychological factors were assessed using self-reported questionnaires. Self-efficacy for PA

145 was assessed using a five-item measure. The participants indicated the extent to which they were

146 confident in their ability to perform planned PA in the face of psychological barriers (i.e., feeling

147 tired, depressed, anxious, angry, and stressed) on a seven-point scale from 1 ("not at all

148 confident") to 7 ("very confident"). The scale is a shortened and moderated version of the

149 original instrument developed by Bandura (2001). The version used in this study has

150 demonstrated excellent internal consistency with a Cronbach alpha coefficient of 0.91 (Hansen et

151 al., 2014). Another five-item measure was used to assess perceived behavioural control. The

152 participants rated their agreement with three positive (e.g., "I have total control over being

153 regularly physically active") and two negative statements (e.g., "Being regularly physically active

154 is difficult for me") on a seven-point scale from 1 ("totally agree") to 7 ("don't agree at all"). The

155 scale is an extended and moderated version of the original instrument developed by Norman \&

156 Smith (1995). The version used in this study has demonstrated acceptable internal consistency

157 with a Cronbach alpha coefficient of 0.67 (Hansen et al., 2014). PA self-identity was assessed 
158 using a three-item measure. The participants indicated the extent to which they agreed with

159 statements such as "Being physically active is a big part of who I am" on a five-point scale from

1601 ("fits poorly") to 5 ("fits well"). The scale is a shortened and moderated version of the original

161 instrument developed by Anderson \& Cychosz (1994). The version used in this study has

162 demonstrated excellent internal consistency with a Cronbach alpha coefficient of 0.91 (Hansen et

163 al., 2014). All three instruments have shown positive cross-sectional associations with objectively

164 assessed PA in adults (Hansen et al., 2014).

\section{Physical activity}

166 PA was measured using the accelerometer Actigraph GTI M (Actigraph, Fort Walton Beach, FL,

167 USA), which is a hip-worn electronic movement sensor that converts acceleration into the

168 arbitrary unit "counts". The counts increase with the magnitude of the work rate for walking. The

169 participants were instructed to wear the accelerometer on the right hip for seven consecutive

170 days, except while sleeping or during water activities. The second assessment was completed

171 towards the end of the first residential stay whereas the others took place in home periods (Figure

172 1). The data were analysed with the Actigraph software ActiLife v. 5.3. A wear-time of $\geq$ ten

173 hours per day for $\geq$ four days was the criterion for a valid measure. Periods of $\geq 60$ consecutive

174 minutes without counts were defined as non-wear-time, allowing for up to two minutes of counts

175 greater than zero within these 60 minutes (Trost, McIver \& Pate, 2005; Sirard et al., 2011). The

176 counts were summed and averaged over the total wear-time to indicate the overall PA in counts

177 per minute (CPM). The accelerometer has been found to be valid in severely obese adults

178 (Aadland \& Anderssen, 2012) and accelerometer-assessed PA has superior validity compared to

179 self-reported data (Prince et al., 2008).

180 Socio-demographic information and anthropometry 
181 Socio-demographic information was obtained from questionnaires. Height was measured without

182 shoes to the nearest $0.5 \mathrm{~cm}$ with a wall mounted stadiometer (SECA, Germany). Weight was

183 measured on a bioelectrical impedance analysis device (BC 420S MA, Tanita Corp, Tokyo,

184 Japan) and reported to the nearest $0.1 \mathrm{~kg}$.

185 Ethics

186 Written informed consent was obtained from all participants prior to the data collection, in 187 accordance with the Helsinki Declaration. Ethical approval was obtained from the Regional

188 Committee for Medical and Health Research Ethics for South-East Norway (registration number 189 2010/159).

190 Statistical analysis

191 Before calculating the mean values for the psychological factors, the three positively worded 192 items for perceived behavioural control were reversed. Thus, higher mean values indicated 193 stronger self-efficacy, perceived control, and identity. Cronbach alpha was used to determine the 194 internal consistency of the instruments.

195 Data on civil status were dichotomized into "married/cohabiting" vs "single/divorced", 196 educational level into " $<15$ years of education" vs " $\geq 15$ years of education" (i.e., 197 college/university), and employment into "not working" (i.e., being unemployed or receiving 198 pensions or benefits) vs "working”. BMI was calculated as weight in kilograms divided by the 199 square of the height in meters.

200 A linear mixed model based on restricted maximum likelihood estimation with random 201 intercept for subjects was used in all analyses for change over time (Twisk, 2003), using least 202 significant difference from baseline. Effect size (ES) for change was calculated by subtracting the 203 two-year score from the baseline score, divided by the standard deviation (SD) at baseline. ES 
204 were judged against the standard criteria proposed by Cohen: Small change $(0.2$ to $<0.5)$,

205 moderate change $(0.5$ to $<0.8)$, and large change $(\geq 0.8)($ Ellis, 2011).

206 The associations between the independent variables: $\Delta$ self-efficacy for PA in the face of

207 psychological barriers, $\Delta$ perceived behavioural control over PA, and $\Delta$ PA self-identity and the

208 dependent variable of $\Delta \mathrm{PA}$ were analysed using linear regression, applying delta scores between

209 time points $\left(\Delta y_{1}=y_{1}-y_{0} ; \Delta x_{1}=x_{1}-x_{0} ; \Delta y_{2}=y_{2}-y_{1}\right.$, etc.) (Twisk, 2003). For the independent

210 and dependent variables and BMI, the differences between baseline and week six $(\Delta 1)$, between

211 week six and year one $(\Delta 2)$, and between year one and year two $(\Delta 3)$ were used. The linear

212 mixed model was omitted because the interpretation of the regression coefficients in such a

213 model is difficult, due to mixing of longitudinal (with-in subject) changes and the cross-sectional

214 (between-subject) differences (Twisk, 2003). Age, gender, and $\Delta$ BMI served as covariates in the

215 multiple regression analyses. A total of $N=71$ observations was included in the regression

216 analyses. Residuals were normally distributed in all models.

217 Baseline subject characteristics are presented as percentages for categorical data and mean 218 values (SD) for continuous variables. The estimates, obtained from the linear mixed model, for

219 the psychological factors, PA, and BMI are presented as means with $95 \%$ confidence intervals

220 (CI) for the four assessment points. We performed a drop-out analysis with the chi-squared test

221 for difference in gender and the independent samples $t$-test for differences in other variables.

222 The statistical analyses were done using SPSS v. 20.0 (SPSS Inc., Chicago, USA). A two-

223 sided $p$-value $\leq 0.05$ indicated statistical significance.

\section{Results}

225 Forty-nine patients (37 women, 75.5\%) consented to participate in the study. Baseline

226 characteristics are presented in Table 1. Other details of the participants have been presented

227 previously (Jepsen et al., 2013; Aadland et al., 2014). 

twenty-two participants (44.9\%, 16 women and six men) were lost to follow-up. Reasons for dropping out of the intervention included pregnancy, referral to obesity surgery, having reached personal weight goal, health problems, or obligations that interfered with the intervention. Six participants dropped out for unknown reasons and five withdrew from the study due to problems with the study protocol (repeated blood tests and assessments of maximal oxygen consumption which were included in the Haugland Obesity Study). The participants lost to follow-up did not differ from those who completed the study with regards to gender, age, BMI, PA, or psychological factors at baseline, or initial changes (during the first six weeks) in BMI, PA, or psychological factors. Missing data for psychological factors resulted from participants being absent when the questionnaires were administered at RKHRC. Furthermore, some of the accelerometer-obtained data failed to fulfil the validity requirements. self-identity, calculated at baseline, were acceptable to excellent using Cronbach alpha coefficients of $0.92,0.67$, and 0.93 , respectively.

Table 2 shows that PA increased significantly from baseline to the end of the first residential

244 period and remained increased at the one-year follow-up. However, after two years the increase

245 in PA was not maintained $(\mathrm{ES}=0.24)$. All three psychological factors were significantly

246 strengthened at the end of the first residential period (Table 2). However, self-efficacy for PA in

247 the face of psychological barriers decreased thereafter and at one year the improvement had

248 vanished $(\mathrm{ES}=0.14)$. In contrast, perceived behavioural control over PA $(\mathrm{ES}=0.51)$ and PA self-

249 identity $(\mathrm{ES}=0.74)$ remained stronger at year one and two. Compared to baseline, BMI was

250 significantly lower at the three subsequent assessments. However, the weight loss achieved

251 during the first year was only partly maintained at year two (Table 2). The mean weight loss from 252 baseline constituted $4.8 \%$ after six weeks, $6.4 \%$ at year one, and $3.3 \%$ at year two. 
Table 3 shows the associations between change in the psychological factors and $\Delta$ PA over the

254 255

256

257

258

259

260

261

262

263

264

265

266

267

268

269

270

$271 \&$ Gross, 2009) and overweight and obese adolescents (Plotnikoff et al., 2013). However, to our

272 knowledge, no studies have examined this variable during lifestyle interventions and related it to

$273 \Delta$ PA.

274 Although self-efficacy, as such, is a global concept (Bandura, 1997) the measure used in this

275 study was limited to self-efficacy in the face of psychological barriers to PA. The initial

276 strengthening had disappeared at later assessments and was not associated with behaviour 
277 change. This could be interpreted as if the intervention did not target or succeed in strengthening

278 self-efficacy in the face of psychological barriers, or it may indicate that psychological barriers

279 did not play a central role in the PA of these subjects. Other barriers, such as time limitations,

280 which we have not investigated, may be of greater significance (Biddle \& Fox, 1998). Still, a

281 longitudinal study found a positive relationship between moods and PA in overweight to obese

282 adults with diabetes. However, the data were reported by lifestyle coaches, not patients (Venditti

283 et al., 2014), implying a possible responder bias (Ahmed et al., 2012).

284 Next, the intervention strengthened the PA self-identity with a moderate ES (Ellis, 2011).

285 Embarrassment, poor experience, and non-identification with PA may be obstacles to PA in obese 286 adults (Biddle \& Fox, 1998; Hills \& Byrne, 2006). So the strengthening of PA identity could be 287 regarded as positive (Biddle \& Fox, 1998). However, in our study we could not confirm that 288 strengthened identity translates into more PA. In community samples, PA identity has shown 289 positive correlations with objectively measured (Hansen et al., 2014) and self-reported (Jackson, 290 Smith \& Conner, 2003) PA. Thus, this phenomenon deserves attention in future research and in 291 clinical practice.

292 Regarding the impact of body weight, cross-sectional data have demonstrated an adverse 293 relationship between BMI and objectively assessed PA (Hansen et al., 2013) and BMI and 294 perceived behavioural control over PA (Caperchione et al., 2008). However, when controlling for $295 \Delta$ BMI, $\Delta$ perceived behavioural control and $\Delta$ PA still showed associations in the present study. 296 Overall, the findings suggest that factors associated with PA in community samples (Jackson, 297 Smith \& Conner, 2003; Lorentzen, Ommundsen \& Holme, 2007; Hansen et al., 2014) should not 298 be generalised to samples of severely obese adults in lifestyle interventions without caution and 299 testing. Social and environmental factors, including family, work place, and community, may 300 predict and mediate the mechanisms of change in PA in this population (Vartanian \& Shaprow, 
301 2008; Wiklund, Olsén \& Willén, 2011). Thus, future research could take broader perspectives and 302 adopt an ecological approach (Bauman et al., 2012).

303 Our study confirms the findings from other studies (Borg et al., 2002; Tate et al., 2007) that

304 maintenance of PA is an unresolved challenge. With regards to the overall PA, the initial and year 305 two PA (Table 2) were similar to the PA of American obese adults (288 CPM) (Tudor-Locke et 306 al., 2010) and their Norwegian counterparts (women: 276 CPM, men: 290 CPM) (Hansen et al., 307 2013), whereas the mean value from the second assessment (Table 2) was well above the 344 308 CPM for American normal weight (Tudor-Locke et al., 2010) and 352 CPM for women and 368 309 CPM for men of normal weight in Norway (Hansen et al., 2013).

310 Regarding weight loss, the one-year reduction of BMI (Table 2) was within the criterion for 311 success, defined as 5-10\% reduction from the start of an intervention (Tsigos et al., 2008; Dalle 312 Grave, Calugi \& El Ghoch, 2013). However, patients had regained some of the weight at year 313 two which is a common challenge in lifestyle interventions (Dalle Grave, Calugi \& El Ghoch, 314 2013).

315 The present study offered novelty and strength as it used data from four time points and 316 therefore could provide information about patterns of change throughout the two-year 317 intervention. In addition, assessing PA objectively with accelerometers is superior to self-reported 318 PA (Prince et al., 2008). However, accelerometers fail to capture water activities, bicycling, and 319 strength training (Warren et al., 2010). For the present study, this limitation probably caused a $32025 \%$ underestimation of the true overall PA for the second assessment (Aadland et al., 2014), as

321 such activities were common during the residential period. Still, for the purpose of the study, we 322 decided to avoid reporting of intensity-specific PA, due to difficulties of interpretation when 323 applying count thresholds to separate different intensities of PA generally (Orme et al., 2014) and 324 in the severely obese population specifically (Aadland \& Steene-Johannessen, 2012).

325 Underestimation of PA was probably a minor problem when assessing trends over the home 
periods, because patients generally did not engage in such activities (Aadland \& Robertson,

327 2012), and because the underestimation would be equally distributed over time.

328 The main weakness of this study was the relatively high proportion of drop-outs and missing

329 data. Although the drop-out analysis did not reveal differences between the completers and the

330 non-completers, bias cannot be ruled out. However, by using the mixed model based on

331 maximum likelihood estimation and including all valid observations from all four time points, the

332 statistical power increased. Still, our results are based on associations and thus, causal

333 relationships cannot be inferred. Lastly, the participants were a self-selected, treatment-seeking

334 group, participating in a specific intervention programme and there was no control group. While

335 common in clinical studies, these weaknesses limit the generalisability of our results. For

336 transparency and usefulness, we have therefore attempted to report rigorously on the intervention

337 and the flow of the participants (Vandenbroucke et al., 2007).

\section{Conclusion}

339 Little is known about factors related to the process of change of PA behaviour in severely obese

340 adults participating in lifestyle interventions. We hypothesised that the independent variables: $\Delta$

341 self-efficacy for PA, $\Delta$ perceived behavioural control over PA, and $\Delta$ PA self-identity would be

342 associated with the dependent variable of $\Delta \mathrm{PA}$ in the sample of severely obese adults who

343 participated in a two-year programme. However, such an association was only confirmed

344 between $\Delta$ perceived behavioural control and $\Delta \mathrm{PA}$. More research is required to investigate PA

345 behaviour change processes in severely obese both in non-residential and residential settings and

346 with larger samples and stronger design. An ecological framework may provide a good structure

347 (Bauman et al., 2012), with both quantitative and qualitative methods being suitable.

348 The findings of the present study indicate that perceived behavioural control may be a valid 349 target for increase and maintenance of PA in severely obese adults. 


\section{Acknowledgements}

351 We thank the staff at RCHRC for their assistance in the data collection and express our sincere

352 gratitude to the participants.

\section{Conflict of interest}

354 The authors have no conflict of interest to declare. 
356

357

358

359

360

361

362

363

364

365

366

367

368

369

370

371

372

373

374

375

376

377

378

379

380

381

382

383

384

385

386

387

388

389

390

391

392

393

394

395

396

397

398

399

400

401

402
Aadland E, and Anderssen SA. 2012. Treadmill calibration of the Actigraph GT1M in young-tomiddle-aged obese-to-severely obese subjects. Journal of Obesity 2012:318176.

Aadland E, Jepsen R, Andersen JR, and Anderssen SA. 2014. Differences in fat loss in response to physical activity among severely obese men and women. Journal of Rehabilitation Medicine 46:363-369.

Aadland E, and Robertson L. 2012. Physical activity is associated with weight loss and increased cardiorespiratory fitness in severely obese men and women undergoing lifestyle treatment. Journal of Obesity 2012:810594.

Aadland E, and Steene-Johannessen J. 2012. The use of individual cut points from treadmill walking to assess free-living moderate to vigorous physical activity in obese subjects by accelerometry: is it useful? BMC Medical Research Methodology 12:172.

Ahmed S, Berzon RA, Revicki DA, Lenderking WR, Moinpour CM, Basch E, Reeve BB, Wu AW, and International Society for Quality of Life Research. 2012. The use of patientreported outcomes (PRO) within comparative effectiveness research: implications for clinical practice and health care policy. Medical Care 50:1060-1070.

Ajzen I, and Madden TJ. 1986. Prediction of goal-directed behavior: attitudes, intentions, and perceived behavioral control. Journal of Experimental Social Psychology 22:453-474.

Anderson DF, and Cychosz CM. 1994. Development of an exercise identity scale. Perceptual and Motor Skills 78:747-751.

Anderson JW, Conley SB, and Nicholas AS. 2007. One hundred pound weight losses with an intensive behavioral program: changes in risk factors in 118 patients with long-term follow-up. American Journal of Clinical Nutrition 86:301-307.

Bandura A. 1997. Self-efficacy: the exercise of control. New York: Freeman.

Bandura A. 2001. Guide for constructing self-efficacy scales. Stanford: Stanford University.

Bauman AE, Reis RS, Sallis JF, Wells JC, Loos RJ, Martin BW, and Lancet Physical Activity Series Working Group. 2012. Correlates of physical activity: why are some people physically active and others not? Lancet 380:258-271.

Becker W, Lyhne N, Pedersen AN, Aro A, Fogelholm M, Phórsdottir I, Alexander J, Anderssen SA, Meltzer HM, and Pedersen JI. 2004. Nordic nutrition recommendations 2004 -integrating nutrition and physical activity. Scandinavian Journal of Nutrition 48:178-187.

Biddle SJ, and Fox KR. 1998. Motivation for physical activity and weight management. International Journal of Obesity and Related Metabolic Disorders 22 Suppl 2:S39-47.

Bond DS, Evans RK, DeMaria E, Wolfe L, Meador J, Kellum J, Maher J, and Warren BJ. 2006. Physical activity and quality of life improvements before obesity surgery. American Journal of Health Behavior 30:422-434.

Borg P, Kukkonen-Harjula K, Fogelholm M, and Pasanen M. 2002. Effects of walking or resistance training on weight loss maintenance in obese, middle-aged men: a randomized trial. International Journal of Obesity and Related Metabolic Disorders 26:676-683.

Butryn ML, Webb V, and Wadden TA. 2011. Behavioral treatment of obesity. Psychiatric Clinics of North America 34:841-859.

Caperchione CM, Duncan MJ, Mummery K, Steele R, and Schofield G. 2008. Mediating relationship between body mass index and the direct measures of the Theory of Planned Behaviour on physical activity intention. Psychology, Health \& Medicine 13:168-179.

Catenacci VA, and Wyatt HR. 2007. The role of physical activity in producing and maintaining weight loss. Nature Clinical Practice: Endocrinology \& Metabolism 3:518-529.

Charng HW, Piliavin JA, and Callero PL. 1988. Role-identity and reasoned action in the prediction of repeated behavior. Social Psychology Quarterly 51:303-317. 
403

404

405

406

407

408

409

410

411

412

413

414

415

416

417

418

419

420

421

422

423

424

425

426

427

428

429

430

431

432

433

434

435

436

437

438

439

440

441

442

443

444

445

446

447

448

449

450
Christiansen B, Borge L, and Fagermoen MS. 2012. Understanding everyday life of morbidly obese adults-habits and body image. International Journal of Qualitative Studies on Health and Well-being 7:17255.

Dalle Grave R, Calugi S, and El Ghoch M. 2013. Lifestyle modification in the management of obesity: achievements and challenges. Eating and Weight Disorders 18:339-349.

Danielsen KK, Svendsen M, Maehlum S, and Sundgot-Borgen J. 2013. Changes in body composition, cardiovascular disease risk factors, and eating behavior after an intensive lifestyle intervention with high volume of physical activity in severely obese subjects: a prospective clinical controlled trial. Journal of Obesity 2013:325464.

Ellis PD. 2011. The essential guide to effect sizes: statistical power, meta-analysis and the interpretation of research results. Cambridge: Cambridge University Press.

Fogelholm M. 2010. Physical activity, fitness and fatness: relations to mortality, morbidity and disease risk factors. A systematic review. Obesity Reviews 11:202-221.

Goodpaster BH, DeLany JP, Otto AD, Kuller L, Vockley J, South-Paul JE, Thomas SB, Brown J, McTigue K, Hames KC, Lang W, and Jakicic JM. 2010. Effects of diet and physical activity interventions on weight loss and cardiometabolic risk factors in severely obese adults: a randomized trial. JAMA 304:1795-1802.

Hagger MS, Chatzisarantis NLD, and Biddle SJH. 2002. A meta-analytic review of the theories of reasoned action and planned behavior in physical activity: Predictive validity and the contribution of additional variables. Journal of Sport \& Exercise Psychology 24:3-32.

Hansen BH, Holme I, Anderssen SA, and Kolle E. 2013. Patterns of objectively measured physical activity in normal weight, overweight, and obese individuals (20-85 years): a cross-sectional study. PloS One 8:e53044.

Hansen BH, Ommundsen Y, Holme I, Kolle E, and Anderssen SA. 2014. Correlates of objectively measured physical activity in adults and older people: a cross-sectional study of population-based sample of adults and older people living in Norway. International Journal of Public Health 59:221-230.

Hills AP, and Byrne NM. 2006. State of the science: a focus on physical activity. Asia Pacific Journal of Clinical Nutrition 15 Suppl:40-48.

Hunt HR, and Gross AM. 2009. Prediction of exercise in patients across various stages of bariatric surgery: a comparison of the merits of the theory of reasoned action versus the theory of planned behavior. Behavior Modification 33:795-817.

Jackson C, Smith RA, and Conner M. 2003. Applying an extended version of the theory of planned behaviour to physical activity. Journal of Sports Sciences 21:119-133.

Jepsen R, Aadland E, Andersen JR, and Natvig GK. 2013. Associations between physical activity and quality of life outcomes in adults with severe obesity: a cross-sectional study prior to the beginning of a lifestyle intervention. Health and Quality of Life Outcomes 11:187.

Johnson LK, Andersen LF, Hofso D, Aasheim ET, Holven KB, Sandbu R, Roislien J, and Hjelmesaeth J. 2013. Dietary changes in obese patients undergoing gastric bypass or lifestyle intervention: a clinical trial. British Journal of Nutrition 110:127-134.

Karlsen TI, Lund RS, Roislien J, Tonstad S, Natvig GK, Sandbu R, and Hjelmesaeth J. 2013. Health related quality of life after gastric bypass or intensive lifestyle intervention: a controlled clinical study. Health and Quality of Life Outcomes 11:17.

Karlsen TI, Sohagen M, and Hjelmesaeth J. 2013. Predictors of weight loss after an intensive lifestyle intervention program in obese patients: a 1-year prospective cohort study. Health and Quality of Life Outcomes 11:165.

Kay SJ, and Fiatarone Singh MA. 2006. The influence of physical activity on abdominal fat: a systematic review of the literature. Obesity Reviews 7:183-200. 
451

452

453

454

455

456

457

458

459

460

461

462

463

464

465

466

467

468

469

470

471

472

473

474

475

476

477

478

479

480

481

482

483

484

485

486

487

488

489

490

491

492

493

494

495

496

497

498
Kirk SF, Penney TL, McHugh TL, and Sharma AM. 2012. Effective weight management practice: a review of the lifestyle intervention evidence. International Journal of Obesity (2005) 36:178-185.

Kissler HJ, and Settmacher U. 2013. Bariatric surgery to treat obesity. Seminars in Nephrology 33:75-89.

Lee S, Kuk JL, Davidson LE, Hudson R, Kilpatrick K, Graham TE, and Ross R. 2005. Exercise without weight loss is an effective strategy for obesity reduction in obese individuals with and without Type 2 diabetes. Journal of Applied Physiology (1985) 99:1220-1225.

Lerdal A, Andenaes R, Bjornsborg E, Bonsaksen T, Borge L, Christiansen B, Eide H, Hvinden K, and Fagermoen MS. 2011. Personal factors associated with health-related quality of life in persons with morbid obesity on treatment waiting lists in Norway. Quality of Life Research 20:1187-1196.

Lorentzen C, Ommundsen Y, and Holme I. 2007. Psychosocial correlates of stages of change in physical activity in an adult community sample. European Journal of Sport Science 7:93106.

Midthjell K, Lee CM, Langhammer A, Krokstad S, Holmen TL, Hveem K, Colagiuri S, and Holmen J. 2013. Trends in overweight and obesity over 22 years in a large adult population: the HUNT Study, Norway. Clinical Obesity 3:12-20.

Norman P, and Smith L. 1995. The theory of planned behavior and exercise: an investigation into the role of prior behavior, behavioral intentions and attitude variability. European Journal of Social Psychology 25:403-415.

Norwegian Directorate of Health. 2009. [Sykelig overvekt: Prioriteringsveileder.] Oslo: Norwegian Directorate of Health.

Olander EK, Fletcher H, Williams S, Atkinson L, Turner A, and French DP. 2013. What are the most effective techniques in changing obese individuals' physical activity self-efficacy and behaviour: a systematic review and meta-analysis. International Journal Behavioral Nutrition and Physical Activity 10:29.

Orme M, Wijndaele K, Sharp SJ, Westgate K, Ekelund U, and Brage S. 2014. Combined influence of epoch length, cut-point and bout duration on accelerometry-derived physical activity. International Journal of Behavioral Nutrition and Physical Activity 11:34.

Plotnikoff RC, Lubans DR, Costigan SA, and McCargar L. 2013. A test of the theory of planned behavior to predict physical activity in an overweight/obese population sample of adolescents from Alberta, Canada. Health Education and Behavior 40:415-425.

Prince SA, Adamo KB, Hamel ME, Hardt J, Connor Gorber S, and Tremblay M. 2008. A comparison of direct versus self-report measures for assessing physical activity in adults: a systematic review. International Journal of Behavioral Nutrition and Physical Activity 5:56.

Shaw K, O'Rourke P, Del Mar C, and Kenardy J. 2005. Psychological interventions for overweight or obesity. Cochrane Database of Systematic Reviews:CD003818.

Sirard JR, Forsyth A, Oakes JM, and Schmitz KH. 2011. Accelerometer test-retest reliability by data processing algorithms: results from the Twin Cities Walking Study. Journal of Physical Activity \& Health 8:668-674.

Sparks P, Guthrie CA, and Shepherd R. 1997. The dimensional structure of the perceived behavioral control construct. Journal of Applied Social Psychology 27:418-438.

Sturm R. 2007. Increases in morbid obesity in the USA: 2000-2005. Public Health 121:492-496.

Swinburn BA, Sacks G, Hall KD, McPherson K, Finegood DT, Moodie ML, and Gortmaker SL. 2011. The global obesity pandemic: shaped by global drivers and local environments. Lancet 378:804-814. 
499

500

501

502

503

504

505

506

507

508

509

510

511

512

513

514

515

516

517

518

519

520

521

522

523

524

525

526

527

528

529

530

531

532

533

534
Tate DF, Jeffery RW, Sherwood NE, and Wing RR. 2007. Long-term weight losses associated with prescription of higher physical activity goals. Are higher levels of physical activity protective against weight regain? American Journal of Clinical Nutrition 85:954-959.

Trost SG, McIver KL, and Pate RR. 2005. Conducting accelerometer-based activity assessments in field-based research. Medicine and Science in Sports and Exercise 37:S531-543.

Tsigos C, Hainer V, Basdevant A, Finer N, Fried M, Mathus-Vliegen E, Micic D, Maislos M, Roman G, Schutz Y, Toplak H, Zahorska-Markiewicz B, and Obesity Management Task Force of the European Association for the Study of Obesity. 2008. Management of obesity in adults: European clinical practice guidelines. Obesity Facts 1:106-116.

Tudor-Locke C, Brashear MM, Johnson WD, and Katzmarzyk PT. 2010. Accelerometer profiles of physical activity and inactivity in normal weight, overweight, and obese U.S. men and women. International Journal of Behavioral Nutrition and Physical Activity 7:60.

Twisk JWR. 2003. Applied longitudinal data analysis for epidemiology: a practical guide. Cambridge: Cambridge University Press.

van Nunen AM, Wouters EJ, Vingerhoets AJ, Hox JJ, and Geenen R. 2007. The health-related quality of life of obese persons seeking or not seeking surgical or non-surgical treatment: a meta-analysis. Obesity Surgery 17:1357-1366.

Vandenbroucke JP, von Elm E, Altman DG, Gotzsche PC, Mulrow CD, Pocock SJ, Poole C, Schlesselman JJ, Egger M, and Strobe Initiative. 2007. Strengthening the reporting of observational studies in epidemiology (STROBE): explanation and elaboration. PLoS Medicine 4:e297.

Vartanian LR, and Shaprow JG. 2008. Effects of weight stigma on exercise motivation and behavior: a preliminary investigation among college-aged females. Journal of Health Psychology 13:131-138.

Venditti EM, Wylie-Rosett J, Delahanty LM, Mele L, Hoskin MA, Edelstein SL, and Diabetes Prevention Program Research Group. 2014. Short and long-term lifestyle coaching approaches used to address diverse participant barriers to weight loss and physical activity adherence. International Journal of Behavioral Nutrition and Physical Activity 11:16.

Warren JM, Ekelund U, Besson H, Mezzani A, Geladas N, Vanhees L, and Experts Panel. 2010. Assessment of physical activity - a review of methodologies with reference to epidemiological research: a report of the exercise physiology section of the European Association of Cardiovascular Prevention and Rehabilitation. European Journal of Cardiovascular Prevention and Rehabilitation 17:127-139.

Wiklund M, Olsén MF, and Willén C. 2011. Physical activity as viewed by adults with severe obesity, awaiting gastric bypass surgery. Physiotherapy Research International 16:179186. 


\section{Table 1 (on next page)}

Characteristics of the study sample at baseline, $N=49$

SD: Standard deviation 
Age, mean (SD)

$43.6(9.4)$

Gender, n (\%)

Women

$37(75.5)$

Socio-demographic status, n (\%)

Married/cohabiting

$30(61.2)$

Having children

$27(55.1)$

Formal education $\geq 15$

$22(44.9)$

years

Employed

$41(83.7)$

Anthropometrics, mean (SD)

Body mass index, $\mathrm{kg} / \mathrm{m}^{2}$

$42.1(6.0)$ 


\section{Table 2 (on next page)}

Mixed-effect model estimates: Psychological factors, PA, and BMI during the two-year lifestyle intervention for severely obese adults

Significant $p$-values $(\leq 0.05)$ in bold. aScale 1-7; higher scores represent stronger self-

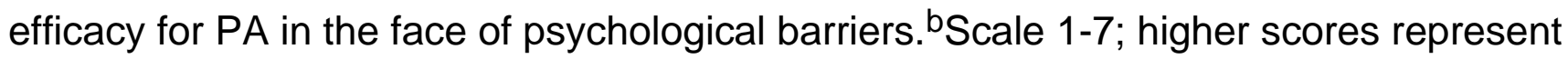
stronger perceived behavioural control over PA. 'Scale 1-5; higher scores represent stronger PA identity. ${ }^{d} p$-values for change from baseline. Physical activity: PA; body mass index: BMI; confidence interval: Cl. 


\begin{tabular}{|c|c|c|c|c|c|c|c|}
\hline & \multirow{2}{*}{$\begin{array}{r}\text { Baseline } \\
\text { Mean (95\% CI) }\end{array}$} & \multicolumn{2}{|c|}{ Week six } & \multicolumn{2}{|c|}{ Year one } & \multicolumn{2}{|c|}{ Year two } \\
\hline & & Mean $(95 \% \mathrm{CI})$ & $p^{\mathrm{d}}$ & Mean $(95 \%$ CI) & $p^{d}$ & Mean $(95 \% \mathrm{CI})$ & $p^{\mathrm{d}}$ \\
\hline \multicolumn{8}{|l|}{ Psychological factors } \\
\hline Self-efficacy for PA in the face of psychological barriers a & $5.1(4.7,5.5)$ & $5.6(4.1,6.0)$ & .029 & $5.4(5.0,5.9)$ & .141 & $5.5(5.0,6.0)$ & .154 \\
\hline Perceived behavioural contrô ${ }^{2}$ over $\mathrm{PA}^{\mathrm{b}}$ & $4.8(4.5,5.1)$ & $5.4(5.0,5.7)$ & .003 & $5.3(4.9,5.7)$ & .026 & $5.4(4.9,5.8)$ & .022 \\
\hline PA identity ${ }^{\mathrm{c}} \quad \sum_{\bar{\sigma}}^{\bar{\sigma}}$ & $2.7(2.5,3.0)$ & $3.1(2.9,3.4)$ & .001 & $3.2(2.9,3.5)$ & $<.001$ & $3.4(3.1,3.7)$ & $<.001$ \\
\hline Accelerometer assessed PA, counts peri minute & $276(241,311)$ & $452(417,486)$ & $<.001$ & $327(286,368)$ & .036 & $290(244,335)$ & .606 \\
\hline.$\stackrel{3}{\frac{3}{2}}$ & $42.1(40.3,43.8)$ & $40.1(38.4,41.8)$ & $<.001$ & $39.4(37.6,41.1)$ & $<.001$ & $40.7(38.9,42.5)$ & .001 \\
\hline
\end{tabular}




\section{Table 3 (on next page)}

Simple and multiple linear regression analysis with $\Delta$ counts per minute as the dependent variable

$\Delta$ : change; regression coefficients: reg. coeff.; confidence interval: $\mathrm{Cl}$; standardized coefficients: stand. coeff.; body mass index: BMI; physical activity: PA

*Number of observations: 71.

Age, gender, $\Delta \mathrm{BMI}$ were included as covariates in the adjusted model.

Significant $p$-values in bold. 


\begin{tabular}{|c|c|c|c|c|c|c|}
\hline & \multirow[b]{2}{*}{ Reg. coeff. $(95 \%$ CI $)$} & \multicolumn{3}{|c|}{ Crude } & \multicolumn{2}{|c|}{ Adjusted* } \\
\hline & & Stand. coeff. & $p$ & Reg. coeff. $(95 \%$ CI $)$ & Stand. coeff. & $p$ \\
\hline Age & $-1.95(-6.45,2.54)$ & -.09 & .390 & $-1.21(-5.66,3.25)$ & -.06 & .590 \\
\hline Gender (refer to women) & $34.73(-66.26,135.72)$ & .08 & .496 & $13.93(-83.85,111.70)$ & .03 & .777 \\
\hline$\Delta \mathrm{BMI}$ & $-44.63(-65.53,-23.74)$ & -.44 & $<.001$ & $-39.08(-61.81,-16.36)$ & -.38 & .001 \\
\hline$\Delta$ self-efficacy for PA $\quad \sum_{\sigma}^{\infty}$ & $28.29(-12.56,69.15)$ & .16 & .172 & $21.84(-16.48,60.17)$ & .13 & .259 \\
\hline$\Delta$ perceived behavioural contre over PA & $66.51(31.40,101.63)$ & .41 & $<.001$ & $51.11(16.17,86.06)$ & .32 & .005 \\
\hline$\Delta$ PA identity & $40.78(-25.11,106.68)$ & .14 & .221 & $-20.14(-85.07,44.80)$ & -.07 & .538 \\
\hline
\end{tabular}




\section{Figure 1}

Flow chart for the two-year follow-up study of severely obese adults in a lifestyle intervention

PA: Physical activity 
Fifty-three subjects invited to participate in the study

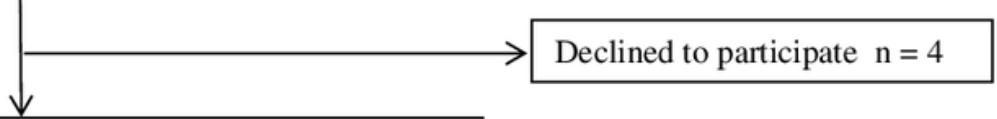

Data collection 1: Prior to the start of the intervention, $N=49$

Data available for analysis:

- Socio-demographic, anthropometric $n=49$

- PA

- Self-efficacy for PA

$\mathrm{n}=42$

- Perceived behavioural control over PA n $=47$

- PA identity

$\mathrm{n}=48$

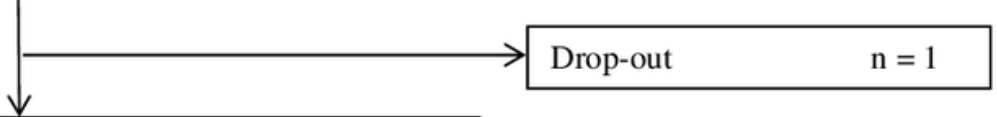

Data collection 2: After six weeks, at the end of the first residential period, $\mathrm{N}=48$

Data available for analysis:

- PA

$\mathrm{n}=43$

- Self-efficacy for PA

$\mathrm{n}=47$

- Perceived behavioural control over PA $n=46$

- PA identity

$\mathrm{n}=46$

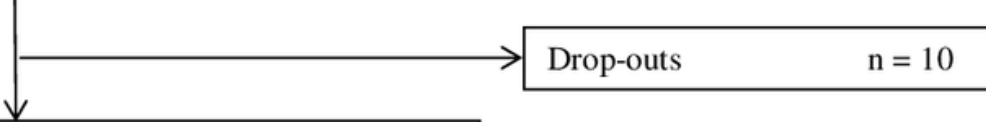

Data collection 3: After one year, before the start of the third residential period, $\mathrm{N}=38$

Data available for analysis:

- PA

$\mathrm{n}=30$

- Self-efficacy for PA

$\mathrm{n}=33$

- Perceived behavioural control over PA $n=33$

- PA identity

$\mathrm{n}=33$

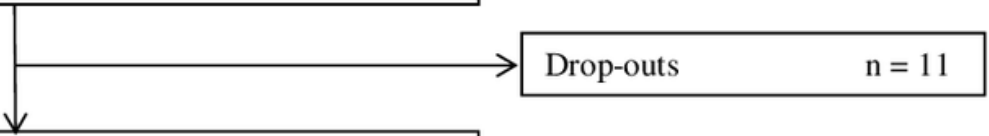

Data collection 4: After two years, before the start of the fourth residential period, $\mathrm{N}=27$

Data available for analysis:

- PA

$\mathrm{n}=24$

- Self-efficacy for PA

$\mathrm{n}=22$

- Perceived behavioural control over PA $n=22$

- PA identity

$\mathrm{n}=22$ 